\title{
Spirostomin, Defense Toxin of the Ciliate Spirostomum teres: Isolation, Structure Elucidation, and Synthesis
}

\author{
Yoshihiko Sera, Miyuki Eiraku Masaki, Matsumi Doe, Federico \\ Buonanno, Akio Miyake, Yoshinosuke Usuki, Hideo Iio
}

\begin{tabular}{|c|l|}
\hline Citation & Chemistry Letters, 44 (5);633-635 \\
\hline Issue Date & 2015 \\
\hline Type & Journal article \\
\hline Text version & author \\
\hline \multirow{2}{*}{ Rights } & $\begin{array}{l}\text { C } 2015 \text { The Chemical Society of Japan. This article may be downloaded for } \\
\text { personal use only. Any other use requires prior permission of The Chemical } \\
\text { Society of Japan. The following article has been submitted to 'Chemistry Letters'. } \\
\text { After it is published, it will be found at https://doi.org/10.1246/cl.150044 }\end{array}$ \\
\hline DOI & \begin{tabular}{l}
$10.1246 / \mathrm{cl} .150044$ \\
\hline
\end{tabular} \\
\hline
\end{tabular}

Self-Archiving by Author(s)

Placed on: Osaka City University

Yoshihiko Sera, Miyuki Eiraku Masaki, Matsumi Doe, Federico Buonanno, Akio Miyake, Yoshinosuke Usuki, Hideo Iio. (2015). Spirostomin, Defense Toxin of the Ciliate Spirostomum teres: Isolation, Structure Elucidation, and Synthesis. Chemistry Letters. 44, 633-635. 


\title{
Spirostomin, Defense Toxin of the Ciliate Spirostomum teres: Isolation, Structure Elucidation, and Synthesis
}

\author{
Yoshihiko Sera, ${ }^{1}$ Miyuki Eiraku Masaki, ${ }^{1}$ Matsumi Doe, ${ }^{1}$ Federico Buonanno, ${ }^{2,3}$ Akio Miyake, ${ }^{2}$ Yoshinosuke Usuki, ${ }^{1}$ and Hideo Iio*1 \\ ${ }^{1}$ Division of Molecular Materials Science, Graduate School of Science, Osaka City University, \\ 3-3-138 Sugimoto, Sumiyoshi-ku, Osaka 558-8585, Japan \\ ${ }^{2}$ Department of Molecular Cellular and Animal Biology, University of Camerino, Via F. Camerini 2, 62032 Camerino \\ $(\mathrm{MC})$, Italy \\ ${ }^{3}$ Department of Education Science, University of Macerata, 62100 Macerata, Italy
}

\section{(E-mail:<iio@sci.osaka-cu.ac.jp)}

The defense toxins, spirostomins $\mathrm{A}$ and $\mathrm{B}$, have been isolated as a diastereomeric mixture from the ciliate microorganism Spirostomum teres. The structure of spirostomin was elucidated through a number of NMR experiments which allowed assigning the unprecedented spiro[(2,5-dimethyl-5,6,7,8-tetrahydronaphthalene-1,4dione)-8,6'-(pyrane-2',5'-dione)] skeleton to this natural compound. The total syntheses of the racemic spirostomins confirmed their structure and relative configurations.

The extrusive organelles (pigment granules) ${ }^{1}$ of the heterotrich ciliate Stentor coeruleus contain a blue pigment stentorin, ${ }^{2}$ while that of Blepharisma japonicum has red pigment blepharismins. ${ }^{3}$ These pigments have been studied as photoreceptors. ${ }^{4}$ Moreover, we recently showed that they constitute a chemical defense system against predators. ${ }^{5,6} \mathrm{We}$ also isolated the defense toxin climacostol from the heterotrich ciliate Climacostomum virens, which has colorless extrusive organelles (cortical granules) ${ }^{7}$ as does Spirostomum teres. We found they had the function of chemical defense against raptorial ciliate Dileptus margaritifer. ${ }^{8}$ The toxic substances, spirostomins A (1) and B (2), were isolated as a 5:1 mixture of diastereomers, and their structures were assigned as spiro[(2,5-dimethyl-5,6,7,8tetrahydronaphthalene-1,4-dione)-8,6'-(pyrane-2',5'-dione)] that is an unprecedented carbon skeleton. Described herein is the isolation, characterization, and syntheses of spirostomins.

Whole cells of Spirostomum teres were dipped in aqueous $70 \% \mathrm{EtOH}$. After removal of the cells by filtration and concentration of the filtrate, the residue was partitioned between ethyl acetate and water. A biologically active fraction, based on lethal toxicity against the ciliate Paramecium caudatum, was collected from the organic layer and purified by preparative TLC. The spirostomins were found as a 5:1 mixture of diastereomers. Further attempts to purify the fraction containing them were not successful due to their instability and low concentration. Lethal dose 50\% $\left(\mathrm{LD}_{50}\right)$ of isolated spirostomins for P. caudatum was $0.25 \mu \mathrm{g}$ $\mathrm{mL}^{-1}$.

The molecular formula of spirostomin was estimated to be $\mathrm{C}_{16} \mathrm{H}_{14} \mathrm{O}_{5}$ as determined by EI-HRMS: $\mathrm{m} / z$. $[\mathrm{M}]^{+}$found 286.0836, calcd 286.0841. This data also suggested that the degree of unsaturation was 10 . The ${ }^{1} \mathrm{H}$ NMR spectrum of the major isomer 1 in $\mathrm{CDCl}_{3}$ exhibited signals due to three $\mathrm{sp}^{2}$ methine protons at $\delta 6.94(\mathrm{~d}, J=10.2 \mathrm{~Hz}), 6.89(\mathrm{~d}, J=10.2$ $\mathrm{Hz})$, and $6.64(\mathrm{q}, \mathrm{br}, J=1.5 \mathrm{~Hz})$, olefinic and aliphatic methyl protons at $\delta 1.99(\mathrm{~d}, J=1.5 \mathrm{~Hz})$ and $1.22(\mathrm{~d}, J=7.1$
$\mathrm{Hz}$ ), respectively, and one methine proton at $\delta 3.10$ (multi). The 16 carbon signals observed in the ${ }^{13} \mathrm{C}$ NMR spectrum were characterized by a DEPT experiment, which suggested that 1 had three $\mathrm{sp}^{2}$ quaternary carbons, three $\mathrm{sp}^{2}$ methines, one oxygenated quaternary carbon, one methine, two methyls, two methylenes, three keto carbonyls, and one ester/lactone carbonyl. These data accounted for 7 out of the 10 degrees of unsaturation, suggesting that 1 was a tricyclic compound. The ${ }^{1} \mathrm{H}-{ }^{1} \mathrm{H}$ COSY, ${ }^{1} \mathrm{H}-{ }^{13} \mathrm{C} \mathrm{HMQC}$, and ${ }^{1} \mathrm{H}-{ }^{13} \mathrm{C}$ HMBC spectra of $\mathbf{1}$ indicated the presence of three structural fragments A, B, and C, as depicted in Figure 1. HMBC correlations from H-3' to C-2' (ester carbonyl, $\left.\delta_{\mathrm{C}} 159.6\right)$ and C-5' (keto carbonyl, $\delta_{\mathrm{C}}$ 194.2) and from H-4' to C-2', and from $\mathrm{H}-3$ and $\mathrm{H}-2_{\mathrm{Me}}$ to $\mathrm{C}-1$ (keto carbonyl, $\delta_{\mathrm{C}} 185.4$ ) connect the $\mathrm{A}$ and $\mathrm{B}$ to the $\mathrm{A}^{\prime}$ and $\mathrm{B}^{\prime}$ fragments, respectively. HMBC correlations from $\mathrm{H}-5, \mathrm{H}-6$, and $\mathrm{H}-5_{\mathrm{Me}}$ to $\mathrm{C}-4 \mathrm{a}$ (quaternary, $\delta_{\mathrm{C}} 151.2$ ), from $\mathrm{H}-6$ and $\mathrm{H}-7$ to $\mathrm{C}-8$ (quaternary, $\delta_{\mathrm{C}} 83.2$ ), and from $\mathrm{H}-5$ and $\mathrm{H}-7$ to $\mathrm{C}-8 \mathrm{a}$ (quaternary, $\delta_{\mathrm{C}} 138.1$ ), suggested that fragment $\mathrm{C}^{\prime}$ was a 6-member ring containing fragment $\mathrm{C}$.

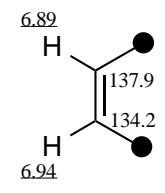

A

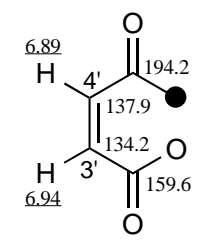

$\mathrm{A}^{\prime}$

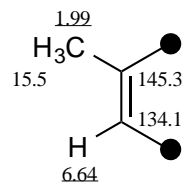

B

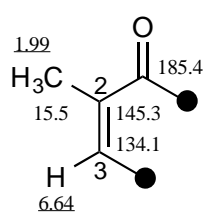

$\mathrm{B}^{\prime}$

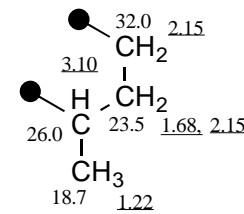

$\mathrm{C}$
Figure 1 Structural fragments for spirostomin

A spiro structure consisting of fragments $\mathrm{A}^{\prime}$ and $\mathrm{C}^{\prime}$ was deduced from HMBC correlations between $\mathrm{H}-7$ and C-5' as well as from $\mathrm{H}-4$ ' to $\mathrm{C}-8$. NOESY correlations also confirmed a through space interaction between $\mathrm{H}-7$ and $\mathrm{H}-4$ '. The tricyclic structure of $\mathbf{1}$ suggested the presence of bicyclic quinone that was formed from a carbonyl carbon $\left(\delta_{\mathrm{C}} 186.0\right)$ and fragments $\mathrm{B}^{\prime}$ and $\mathrm{C}^{\prime}$. Moreover, the UV spectrum of $\mathbf{1}$ $\left(\lambda_{\max } 257 \mathrm{~nm}\right)$ was in closer agreement with that of a paraquinone rather than an ortho-quinone. The synthons were 
then assembled to reveal the planar structure of spirostomin (Figure 2).<smiles>CC1CCC2(OC(=O)C=CC2=O)C2=C1C(=O)C=CC2=O</smiles><smiles>CC1=CC(=O)C2=C(C1=O)C1(CCC2C)OC(=O)C=CC1=O</smiles>

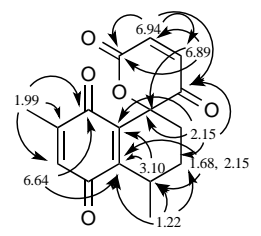

Figure $2{ }^{1} \mathrm{H}$ NMR and ${ }^{13} \mathrm{C} \mathrm{NMR}$ assignment, and $\mathrm{HMBC}$ correlation for spirostomin<smiles>CC1=CC(=O)C2=C(C1=O)[C@@]1(CC[C@@H]2C)OC(=O)C=CC1=O</smiles>

B (2)<smiles>C=C=C=C</smiles>

Scheme 1. Retrosynthesis of spirostomin

The retrosynthetic analysis of spirostomin is depicted in Scheme 1. Pyran ring would be constructed by nucleophilic attack on the carbonyl group with furyllithium and subsequent oxidation. ${ }^{9}$ This approach can be used to build the ring while retaining the stereochemistry of the quaternary carbon. This process also allowed the relative configuration of spirostomin to be assigned from the stereochemistry of the intermediate furan adduct. $\alpha$ Tetralone derivative 5, which had no oxygen functional group at C-8, was selected as a starting material because nucleophilic attack on the benzylic carbonyl carbon was sensitive to the steric effect by the substituent at peri position.

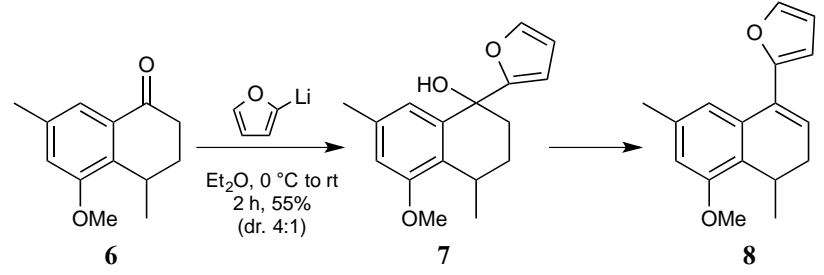<smiles>CCOc1cc(C)cc2c1C(=O)CCC(C)C2=O</smiles>
9 10

11

Scheme 2 Selectivity of furan adducts
$\alpha$-Tetralone derivative $\mathbf{6}^{10}$ was treated with 2furyllithium prepared from furan and $n$-butyllithium, which yielded the corresponding furan adduct 7 as a $4: 1$ mixture of diastereomers (Scheme 2).

In the ${ }^{1} \mathrm{H}$ NMR spectrum of 7 , the signals observed at $\delta$ 7.01 and $6.60 \mathrm{ppm}$ were assigned to $\mathrm{H}-8$ of the major and minor products, respectively. The higher magnetic field signal for the H-8 proton of the minor component can be attributed to the magnetic anisotropy associated with the equatorially bonded furan ring.

In the major product, furan ring and methyl group at the benzylic position are anti to each other. We postulate that this resulted from a favorable axial attack to the carbonyl carbon on the opposite face of the pseudoaxial methyl group. We attempted to separate furan adducts to confirm the stereochemistry. However, not only were the diastereomers of 7 unable to be separated by silica gel column chromatography or preparative TLC, but dehydrated product 8 was also afforded.

We hypothesized that the pseudoaxial methyl group at the remote benzylic position was affected by the steric hinderance of the methoxy group. As such, we expected that an enhancement in selectivity could be achieved during the addition reaction by simply converting the phenolic hydroxyl protecting group from methoxy to the bulkier tertbutyldimethylsilyl group. This conversion provided stabilization to the furan adducts due to the reduced electrondonating nature of the silyloxy group at C-5. $\alpha$-Tetralone derivative 9 was afforded by demethylation of 6 with aq $\mathrm{HBr}$ and acetic acid ${ }^{11}$ and subsequent silylation (69\% in 2 steps) The addition was then repeated on 9, resulting in the formation of the furan adducts $\mathbf{1 0}$ and $\mathbf{1 1}$ in a 10:1 diastereomeric ratio, which were separable by column chromatography. The relative configurations of $\mathbf{1 0}$ and $\mathbf{1 1}$ were determined by the analysis of their ${ }^{1} \mathrm{H}$ NMR and 2DNOESY correlations. In the major product 10, the furan ring and methyl group at the benzylic position were found to be in the anti orientation, as evidenced by the NOESY correlation of $\mathrm{H}-2_{\mathrm{ax}}$ with $\mathrm{H}-4_{\mathrm{Me}}$ and $\mathrm{OH}$ and of $\mathrm{H}-3_{\mathrm{ax}}$ with $\mathrm{H}-$ 3'. On the other hand, in the minor product 11, the NOESY correlation of $\mathrm{H}-2_{\mathrm{ax}}$ with $\mathrm{H}-4_{\mathrm{Me}}$ and $\mathrm{H}-3^{\prime}$ indicated a $s y n$ orientation between the furan ring and the methyl group (Figure 3).

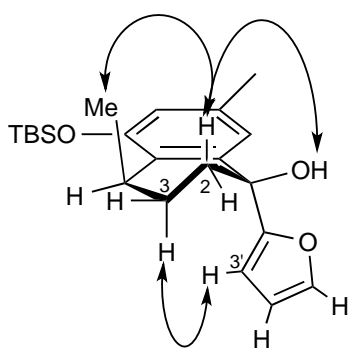

major adduct $(\mathbf{1 0})$

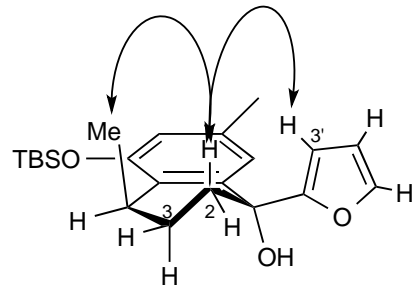

minor adduct (11)
Figure 3 Selected NOESY correlations and conformation of furan adducts $\mathbf{1 0}$ and $\mathbf{1 1}$ 
The Achmatowicz reaction ${ }^{12}$ of $\mathbf{1 0}$ with $m \mathrm{CPBA}$ and subsequent oxidation of the resulting hemiacetal 12 by using equivalent amount of Jones reatgent gave the spiro pyrandione 13. Deprotection of 13 with HF-pyridine afforded phenolic compound 14. Finally, oxidation of 14 with Fremy's salt ${ }^{13,14}$ furnished $\mathbf{1 5}$ and ortho quinone as a byproduct. Interestingly, we found the one-pot synthesis of 15 from 12 without ortho quinone when Jones reagent was used in excess (Scheme 3).

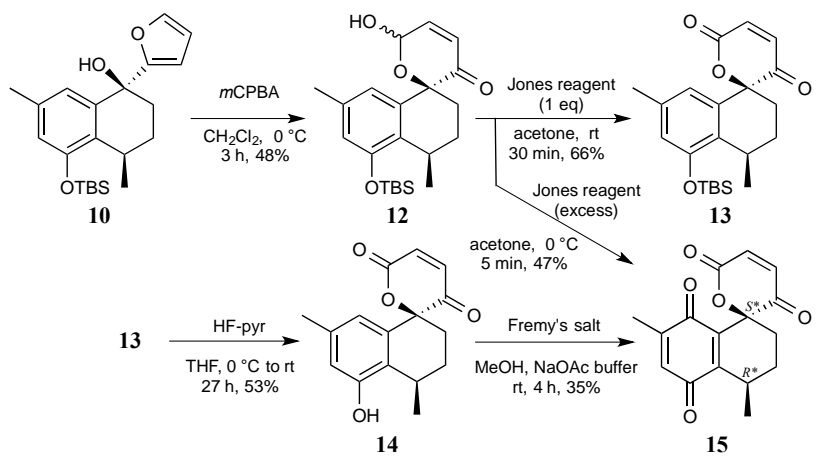

Scheme 3 Synthesis of compounds 13 and $\mathbf{1 5}$

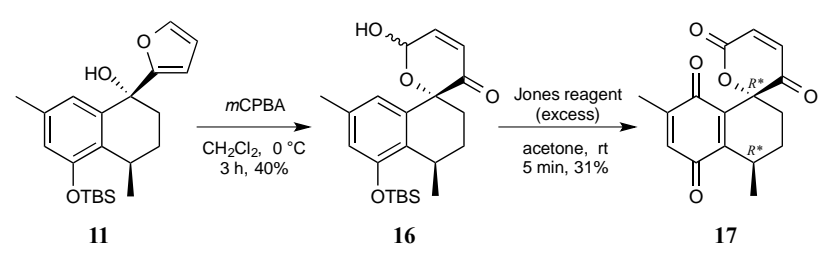

Scheme 4 Synthesis of compound 17

This method was also applied for the synthesis of spirostomin 17 beginning with the minor product 11 (Scheme 4). The fact that conversion of the furan adducts $\mathbf{1 0}$ and 11 yielded stereospecifically 15 and 17, respectively, suggested that epimerization of the benzylic position did not occur under these reaction conditions. The spectral characteristics of synthetic $\mathbf{1 5} 5^{15}$ and $\mathbf{1 7 ^ { 1 6 }}$ were consistent with those observed for the natural spirostomins $\mathrm{B}$ and $\mathrm{A}$, respectively. The relative configurations of spirostomins A and $\mathrm{B}$ were therefore determined as $\left[5 R^{*}, 8 R^{*}\right]$ and $\left[5 R^{*}\right.$, $\left.8 S^{*}\right]$, respectively.

In conclusion, we accomplished the isolation, characterization, and structural elucidation of spirostomin. The relative configurations of two stereogenic centers were confirmed by chemical syntheses of $\mathbf{1 5}$ and $\mathbf{1 7}$. Stereoselective synthesis of spirostomin A and determination of the absolute configurations of spirostomins ${ }^{17}$ will be reported in due course.

This work was supported in part by a Grand-in Aid for Scientific Research (Grand no. 16310154) from the Ministry of Education, Science, Culture and Sports of Japan.

\section{References and Notes}

1 a) V. Tartar, The Biology of Stentor; Pergamon: New York, 1961. b) A. C. Giese, Blepharisma; Stanford University Press: California, 1973
2 N. Tao, M. Orlando, J.-S. Hyon, M. Gross, P.-S. Song, J. Am. Chem. Soc. 1993, 115, 2526-2528.

3 a) G. Checcucci, R. S. Shoemaker, E. Bini, R. Cerny, N. Tao, J.-S Hyon, D. Gioffre, F. Ghetti, F. Lenci, P.-S. Song, J. Am. Chem. Soc. 1997, 119, 5762-5763. b) M. Maeda, H. Naoki, T. Matsuoka, Y. Kato, H. Kotsuki, K. Utsumi, T. Tanaka, Tetrahedron Lett. 1997, 38, 7411-7414. c) D. Spitzner, G. Hofle, I. Klein, S. Pohlan, D. Ammermann, L. Jaenicke, Tetrahedron Lett. 1998, 39, 40034006.

4 a) P.-S. Song, Biochim. Biophys. Acta 1981, 639, 1-29. b) P. Scevoli, F. Bisi, F. Colombetti, F. Ghetti, F. Lenci, B. J. Pasarelli, Photochem. Photobiol. B: Biol. 1987, 1, 75-84. c) T. Matsuoka, Y. Watanabe, Y. Sagara, M. Takayanagi, Y. Kato, Photochem. Photobiol. 1995, 62, 190-193.

5 a) A. Miyake, T. Harumoto, B. Salvi, V. Rivola, Eur. J. Protistol. 1990, 25, 310-315. b) T. Harumoto, A. Miyake, N. Ishikawa, R. Sugibayashi, K. Zenfuku, H. Iio, Eur. J. Protistol. 1998, 34, 458470. c) M. N. Terazima, H. Iio, T. Harumoto, Photochem. Photobiol. 1999, 69, 47-54. d) A. Miyake, T. Harumoto, H. Iio, Eur. J. Protistol. 2001, 37, 77-88.

6 F. Buonanno, G. Guella, C. Strim, C. Ortenzi, Hydrobiologia 2012, 684, 97-107. (This article partly described about spirostomin, but the structure was incorrectly drawn.)

7 a) M. E. Masaki, T. Harumoto, M. N. Terazima, A. Miyake, Y. Usuki, H. Iio, Tetrahedron Lett. 1999, 40, 8227-8229. b) A. Miyake, F. Buonannno, P. Saltalamacchia, M. E. Masaki, H. Iio, Eur. J. Protistol. 2003, 39, 25-36. c) M. E. Masaki, S. Hiro, Y. Usuki, T. Harumoto, M. N. Terazima, F. Buonanno, A. Miyake, H. Iio, Tetrahedron 2004, 60, 7041-7048. d). F. Buonnano, C. Ortenzi, Biologia 2010, 65, 675-680.

8 a) A. Miyake, Jpn. J. Protozool. 2002, 35, 97-117. b). F Buonanno, Ital. J. Zool. 2005, 72, 293-295. c) F. Buonanno, Biologia 2011, 66, 648-653.

9 a) M. P. Georgiadis, A. Sekouras, S. I. Kotretrou, S. A. Horoutouniam, M. G. Polissiou, Synthesis 1991, 929. b) S. V. Kandula, V. G. Puranik, P. Kumar, Tetrahedron Lett. 2003, 44, 5015.

10 H. Tanaka, K. Nobetani, K. Adachi, Chem. Soc. Jpn. 1988, 7, 1065 .

11 J. A. Valderrama, R. Tapia, Sythetic Commun. 1992, 22, 629-639.

12 O. Achmatowicz Jr., P. Bukowski, B. Szechner, Z. Zwierzchowska, A. Zamojski Tetrahedron 1971, 27, 1973-1996.

13 D. J. Cram, R. A. Reeves, J. Am. Chem. Soc. 1958, 80, 3094-3103.

14 H. Iio, H. Nagaoka, Y. Kishi, J. Am. Chem. Soc. 1980, 102, 79657967.

15 Spectra data of 15: ${ }^{1} \mathrm{H}$ NMR $\left(600 \mathrm{MHz}, \mathrm{CDCl}_{3}\right) \delta 1.27(3 \mathrm{H}, \mathrm{d}, J=$ $7.0 \mathrm{~Hz}), 1.69(1 \mathrm{H}$, multi), $1.99(3 \mathrm{H}, \mathrm{d}, J=1.5 \mathrm{~Hz}), 2.01(1 \mathrm{H}$, multi), $2.05(1 \mathrm{H}$, multi), $2.30(1 \mathrm{H}$, multi), $2.99(1 \mathrm{H}$, multi), 6.62 $(1 \mathrm{H}, \mathrm{q}, J=1.5 \mathrm{~Hz}), 6.83(1 \mathrm{H}, \mathrm{d}, J=10.1 \mathrm{~Hz}), 6.95(1 \mathrm{H}, \mathrm{d}, J=$ $10.1 \mathrm{~Hz}) ;{ }^{13} \mathrm{C} \mathrm{NMR}\left(150 \mathrm{MHz}, \mathrm{CDCl}_{3}\right) \delta 15.5,19.6,25.0,27.1$, $31.7,83.9,134.1,134.4,137.1,138.3,145.3,151.6,159.9,185.5$, 186.3, 192.8; HR-EIMS m/z 286.0838 (calcd for $\mathrm{C}_{16} \mathrm{H}_{14} \mathrm{O}_{5}$, 286.0841).

16 Spectra data of 17: ${ }^{1} \mathrm{H}$ NMR $\left(600 \mathrm{MHz}, \mathrm{CDCl}_{3}\right) \delta 1.22(3 \mathrm{H}, \mathrm{d}, J=$ $7.1 \mathrm{~Hz}), 1.70(1 \mathrm{H}$, multi), $1.99(3 \mathrm{H}, \mathrm{d}, J=1.5 \mathrm{~Hz}), 2.13(1 \mathrm{H}$, multi), $2.15(2 \mathrm{H}$, multi), $3.10(1 \mathrm{H}$, multi), $6.64(1 \mathrm{H}, \mathrm{d}, J=1.5 \mathrm{~Hz})$ $6.89(1 \mathrm{H}, \mathrm{d}, J=10.2 \mathrm{~Hz}), 6.94(1 \mathrm{H}, \mathrm{d}, J=10.2 \mathrm{~Hz}) ;{ }^{13} \mathrm{C}$ NMR $\left(150 \mathrm{MHz}, \mathrm{CDCl}_{3}\right) \delta 15.6,18.7,23.5,26.0,31.9,83.2,134.1$, $134.2,137.9,138.1,145.3,151.2,159.6,185.4,186.0,194.2$; HREIMS $m / z 286.0842$ (calcd for $\mathrm{C}_{16} \mathrm{H}_{14} \mathrm{O}_{5}, 286.0841$ )

17 S. Serra, Nat. Prod. Commun. 2013, 8, 863-868. (This article reported about synthesis of (-)-sciffnerone-B that we refered to for synthesis of optically active spirostomin.)

18 Supporting Information is also available electronically on the CSJ-Journal Web site, http://www.csj.jp/journals/chemlett/index.html. 


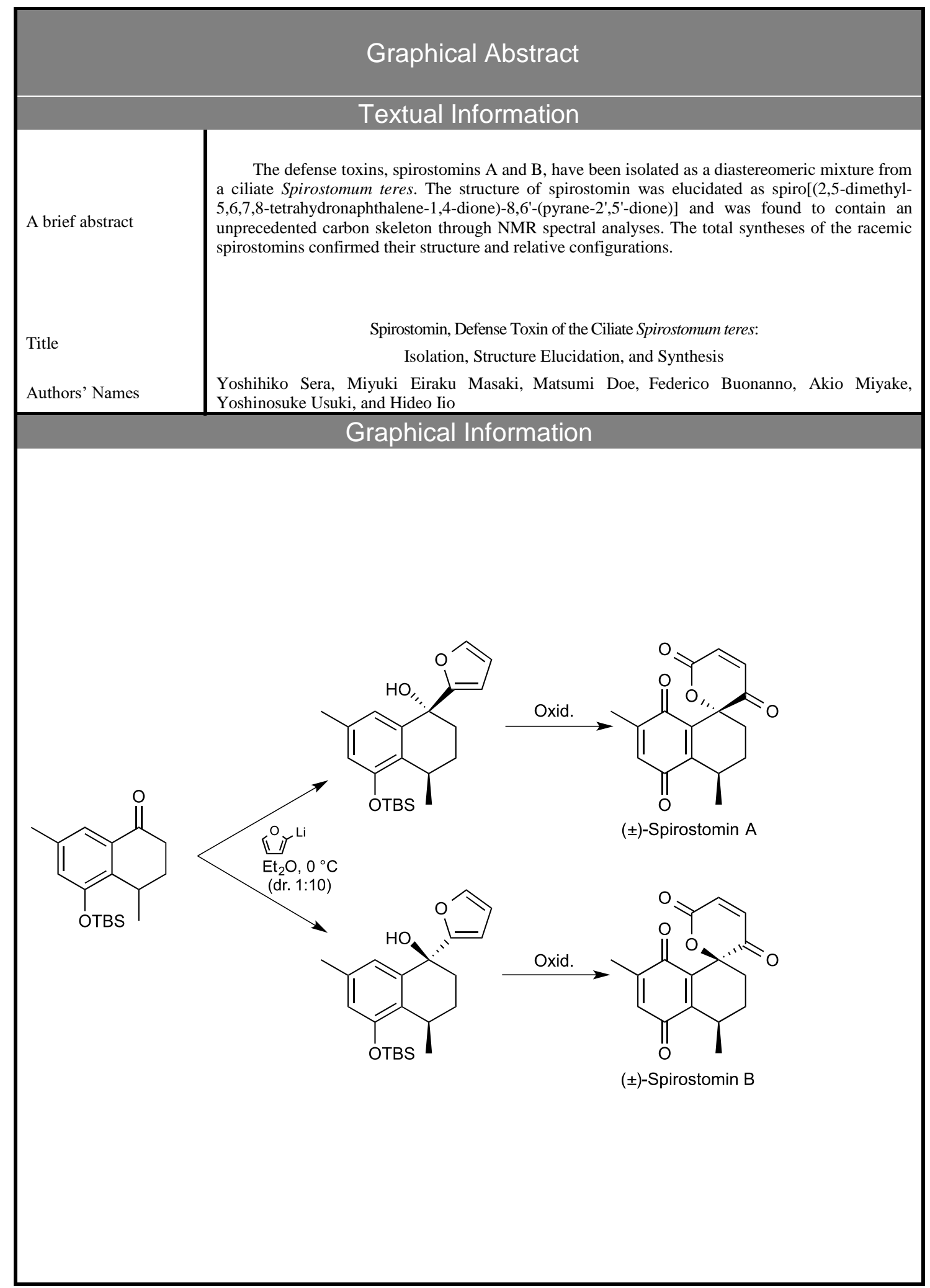

